marker that can be used further to investigate differences in the two main aetiological types of diabetes.

The parallel of our results for type I diabetes with those for ankylosing spondylitis is striking. In both there are strong associations with particular HLA markers and a significant increase in the proportion of non-secretors. This is further indirect evidence to support the suggestion that an infectious agent is implicated in the initiation of type I diabetes in some genetically predisposed patients. Determining the secretor state of patients who have various viral infections would be a useful first step in investigating this hypothesis. We suggest that the initial susceptibility to some viral infections might be greater in the non-immune, non-secretor host. The specific immune response to the putative infectious agent, controlled by the class II HLA DR3/4 genes, might contribute to pathogenic sequelae leading to the diabetic state.

We are grateful to Dr A E Mourant for helpful discussions and to the Edinburgh and South East Scotland Blood Transfusion Service for reagents used in the study.

1 Blackwell CC, Jonsdottir $\mathrm{K}$, Hanson $\mathrm{M}$, et al. Non-secretion of $\mathrm{ABO}$ antigens predisposing to infection by Neisseria meningitidis and Streptococcus pneumoniae. Lancet 1986;ii:284-5.

2 Shinebaum R, Blackwell CC, Forster PJG, et al. Non-secretion of ABO blood group antigens as a host susceptibility factor in the spondyloarthropathies. Br Med f 1987;294:208-10.

3 Bottazo GF. Death of a beta cell: homicide or suicide? Diabetic Medicine 1986;3:119-30.

4 Keen $\mathrm{H}$. The genetics of diabetes: from nightmare to headache. Br Med $\mathcal{f}$ 1987;294:917-9.

5 Mollison PL. Blood transfusion in clinical medicine. Oxford: Blackwell Scientific Publications, 1979:414-82.

(Accepted 17 August 1987)

Department of Bacteriology, The Medical School, University of Edinburgh, Edinburgh EH8 9AG

CCAROLINE BLACKWELL, BSC, PHD, lecturer

VALERIE S JAMES, FIMLS, research technician

DONALD M WEIR, MD, FRCPED, professor

Diabetic and Dietetic Department, Royal Infirmary, Edinburgh EH3 9YW

JOHN D GEMMILL, BSC, MRCP, registrar

ALAN W PATRICK, MRCP, registrar

ANDREW COLLIER, BSC, MRCP, registrar

BASIL F CLARKE, FRCPED, consultant physician

Correspondence to: Dr Blackwell.

\section{Quality of haemofiltration fluids: a potential cause of severe electrolyte imbalance}

Haemofiltration, which requires the infusion of large amounts of electrolyte replacement solutions, is finding increasing application in general hospitals. These solutions do not have a product licence, so responsibility for their quality, safety, and efficacy is taken by the prescriber. We report a case in which the wide limits of quality control of a solution had clinical implications and discuss a survey of the limits of quality control of some commonly used haemofiltration fluids.

\section{Patient, method, and results}

A 73 year old woman was admitted to hospital because of worsening breathlessness and peripheral oedema. She had a history of two mitral valve replacements nine years and two months previously. The clinical findings were severe tricuspid regurgitation with competent aortic and mitral valves. She progressively gained weight in hospital despite diuretics and infusion of dopamine. We decided to perform further tricuspid valve surgery, and to improve her clinical state haemofiltration was performed for $\mathbf{4 8}$ hours before surgery.

She underwent venovenous haemofiltration with a BSM-22 (Hospal UK), with vascular access through a right internal jugular haemofiltration catheter; a Biospal SCU/CAVH filter was used. About 16 litres of haemofiltrate was obtained on each day, with a negative balance of four litres. Fluid replacement through the BSM-22 was with Hemofiltrasol-21, with $8 \mathrm{mmol}$ potassium chloride added to each three litre bag. In addition, she also received two units of human plasma protein fraction for the first 24 hours, $20 \%$ mannitol $100 \mathrm{ml}$ intravenously twice and frusemide $80 \mathrm{mg}$ intravenously once in the second 24 hours, and spironolactone $100 \mathrm{mg}$ once daily.

Her clinical state improved. To our surprise her plasma sodium concentration decreased progressively from $138 \mathrm{mmol} / \mathrm{l}$ at the start of the procedure to 133 $\mathrm{mmol} / 1$ after 48 hours of haemofiltration. Forty eight hours after haemofiltration had stopped her plasma sodium concentration remained at $134 \mathrm{mmol} / \mathrm{l}$. Blood glucose concentration rose from $5.2 \mathrm{mmol} / \mathrm{l}$ (random level) before treatment to $8.4 \mathrm{mmol} / 1$ during haemofiltration. The plasma potassium concentration, supplemented as described above, remained at $3.8 \mathrm{mmol} / \mathrm{l}$. The serum calcium concentration rose from $2.37 \mathrm{mmol} / \mathrm{l}$ to $2.60 \mathrm{mmol} / \mathrm{l}$. There was no appreciable change in the magnesium concentration.

We were surprised by the progressive decrease in plasma sodium concentration during haemofiltration. The Hemofiltrasol-21 bag quoted the sodium concentration as being $140 \mathrm{mmol} / \mathrm{l}$. When a sample of this was analysed on the same flame photometer as the plasma it was found to contain $133 \mathrm{mmol}$ sodium/l. This was confirmed in two other bags of the same batch.

The sodium concentration of $133 \mathrm{mmol} / \mathrm{l}$ is within the limits of quality control of Hemofiltrasol-21. We therefore investigated the limits of quality control fluids from four suppliers in this country. The limits varied widely between manufacturers-for example, the limits of quality control for sodium with one manufacturer were $+3 \%$ to $-3 \%$, while with another they were $+5 \%$ to $-7 \%$. Those of magnesium were $+5 \%$ to $-5 \%$ with one manufacturer and $+13 \%$ to $-13 \%$ with another. The table shows the stated concentration and the limits of some ions.

Concentration (mmolll) of some common ions in haemofiltration fluids (figures in parentheses are limits of quality control)

\begin{tabular}{lcccl}
\hline Supplier & Sodium & Calcium & \multicolumn{1}{c}{ Magnesium } & \multicolumn{1}{c}{ Chloride } \\
\hline 1 & $142(138-146)$ & $2 \cdot 00(1 \cdot 90-2 \cdot 10)$ & $0 \cdot 75(0 \cdot 71-0 \cdot 79)$ & $103 \cdot 0(98 \cdot 0-108 \cdot 0)$ \\
2 & $140(130-147)$ & $1 \cdot 60(1 \cdot 40-1 \cdot 80)$ & $0 \cdot 75(0 \cdot 68-0 \cdot 83)$ & $100 \cdot 0(90 \cdot 0-110 \cdot 0)$ \\
3 & $135(128-142)$ & $1 \cdot 88(1 \cdot 79-1 \cdot 97)$ & $0 \cdot 75(0 \cdot 71-0 \cdot 79)$ & $106 \cdot 5(101 \cdot 2-111 \cdot 8)$ \\
4 & $135(128-142)$ & $1 \cdot 20(1 \cdot 10-1 \cdot 30)$ & $0 \cdot 75(0 \cdot 65-0 \cdot 85)$ & $103 \cdot 0(98 \cdot 0-108 \cdot 0)$ \\
\hline
\end{tabular}

\section{Comment}

The development of hyponatraemia in heart failure is associated with poor prognosis. ${ }^{1}$ The wide limits of quality control applied to some ion concentrations make control of electrolyte balance during haemofiltration unpredictable and potentially hazardous, especially when large volumes are infused. Fluids from suppliers 3 and 4 are within $2 \%$ of their intended ion concentrations at the time of manufacture, though they apply wider limits of quality control at the end of the shelf life owing to the evaporation of water from polyvinylchloride bags.

Doctors must remain alert to electrolyte imbalance caused by variations in fluid constituents during large intravenous infusions. Medicinal products without a product licence are prepared as "specials," made to the clinician's specification. Until a manufacturer obtains a product licence doctors who require haemofiltration fluids should specify not only the required concentration of ions but also the acceptable limits of quality control.

1 Lee WH, Packer $M$. Prognostic importance of serum sodium concentration and its modifications by converting enzyme inhibition in patients with severe chronic heart failure. Circulation converting enzyme

(Accepted 17 August 1987)

\section{National Heart Hospital, London W1M 8BA}

N D BARBER, PHD, MPS, staff pharmacist in charge

J S R GIBBS, MA, MRCP, honorary registrar

P BARRETT, BSC, MPS, pharmacist

K M FOX, MD, MRCP, consultant cardiologist

Correspondence and requests for reprints to: Dr Gibbs.

\section{Increased cough reflex associated with angiotensin converting enzyme inhibitor cough}

Angiotensin converting enzyme inhibitors are being used increasingly to treat hypertension and congestive cardiac failure as they are one of the few treatments that improve life expectancy in these conditions. ${ }^{1}$ In general, these drugs are well tolerated, but recently unexpected and troublesome cough, without obvious pulmonary abnormality, has been reported in as many as $5-10 \%$ of patients taking both captopril and enalapril. ${ }^{2}$ Until recently cough has been difficult to assess, but we have developed a method for measuring the sensitivity of the cough reflex to a standard inhaled stimulus: capsaicin (red pepper). ${ }^{3}$ Using a modification of this method, we assessed the sensitivity of the cough reflex in five patients with cough associated with treatment with angiotensin converting enzyme inhibitors. 